\title{
Randomized controlled split-mouth clinical trial of direct laminate veneers with two micro-hybrid resin composites
}

\author{
Gresnigt, Marco M M ; Kalk, Warner ; Özcan, Mutlu
}

\begin{abstract}
OBJECTIVES: This randomized, split-mouth clinical study evaluated the survival rate of direct laminate veneers made of two resin-composite materials. METHODS: A total of 23 patients (mean age: 52.4 years old) received 96 direct composite laminate veneers using two micro-hybrid composites in combination with two adhesive resins (Ena-Bond-Enamel HFO: $n=48$, Clearfil SE Bond-Miris2: $n=48$ ). Enamel was selectively etched with $38 \% \mathrm{H}(3) \mathrm{PO}(4)$ for 30s, rinsed 30s and the corresponding adhesive resin was applied accordingly. Existing resin composite restorations in good conditions (small or big) were not removed but conditioned using silica coating (CoJet) and silanized (ESPE-Sil). Restorations were evaluated at baseline and thereafter every 6 months. Additional qualitative analysis was performed using modified USPHS criteria. RESULTS: Mean observation period was 41.3 months. Altogether, 12 absolute failures were observed [survival rate: 87.5\%] (Kaplan-Meier). The survival rates with the two resin composites did not show significant differences [Enamel HFO: 81.2\%, Miris2: 93.8\%] ( $>0.05)$. The presence of existing composite restorations on the prepared teeth did not affect the survival rate significantly (intact teeth: $100 \%$, small restorations: $90.6 \%$, big restorations: $82.7 \%)(p>0.05)$. Surface roughness and marginal discolouration were the main qualitative deteriorations observed until the final recall. Secondary caries and endodontic complications did not occur in any of the teeth. CONCLUSION: Early findings of this clinical study with the two micro-hybrid composite laminate veneers showed similar survival rate and their clinical performance was not significantly influenced when bonded onto intact teeth or onto teeth with existing restorations with the protocol applied.
\end{abstract}

DOI: https://doi.org/10.1016/j.jdent.2012.05.010

Posted at the Zurich Open Repository and Archive, University of Zurich

ZORA URL: https://doi.org/10.5167/uzh-75523

Journal Article

Accepted Version

Originally published at:

Gresnigt, Marco M M; Kalk, Warner; Özcan, Mutlu (2012). Randomized controlled split-mouth clinical trial of direct laminate veneers with two micro-hybrid resin composites. Journal of Dentistry, 40(9):766-775.

DOI: https://doi.org/10.1016/j.jdent.2012.05.010 


\section{Randomized controlled split-mouth clinical trial of direct laminate veneers with two micro-hybrid resin composites}

\section{Marco M.M. Gresnigt ${ }^{\mathrm{a}}$, Warner Kalk ${ }^{\mathrm{a}}$, Mutlu Özcan ${ }^{\mathrm{b}}$}

${ }^{a}$ Department of Fixed and Removable Prosthodontics, Center for Dentistry and Oral Hygiene, University Medical Center Groningen, The University of Groningen, Groningen, The Netherlands.

${ }^{b}$ Dental Materials Unit, Center for Dental and Oral Medicine, Clinic for Fixed and Removable Prosthodontics and Dental Materials Science, Zurich, Switzerland.

Short title: Clinical performance of direct composite laminate veneers

*Corresponding author. Dr. Marco Gresnigt, DDS, Department of Fixed and Removable Prosthodontics, Center for Dentistry and Oral Hygiene, University Medical Center Groningen, The University of Groningen, Antonius Deusinglaan 1, 9713 AV, Groningen, The Netherlands. Tel: +31 5036326 08; Fax: +31 5036326 96; E-mail: marcogresnigt@yahoo.com 


\section{ABSTRACT}

Objectives: This randomized, split-mouth clinical study evaluated the survival rate of direct laminate veneers made of two resin-composite materials.

Methods: A total of 23 patients (mean age: 52.4 years old) received 96 direct composite laminate veneers using two micro-hybrid composites in combination with two adhesive resins (Ena-Bond-Enamel HFO: $n=48$, Clearfil SE Bond-Miris2: $n=48$ ). Enamel was selectively etched with $38 \% \mathrm{H}_{3} \mathrm{PO}_{4}$ for 30 seconds, rinsed 30 seconds and the corresponding adhesive resin was applied accordingly. Existing resin composite restorations in good conditions (small or big) were not removed but conditioned using silica coating (CoJet) and silanized (ESPE-Sil). Restorations were evaluated at baseline and thereafter every 6 months. Additional qualitative analysis was performed using modified USPHS criteria.

Results: Mean observation period was 41.3 months. Altogether, 12 absolute failures were observed [survival rate: $87.5 \%$ ] (Kaplan-Meier). The survival rates with the two resin composites did not show significant differences [Enamel HFO: $81.2 \%$, Miris2: 93.8\%] $(p>0.05)$. The presence of existing composite restorations on the prepared teeth did not affect the survival rate significantly (intact teeth: $100 \%$, small restorations: $90.6 \%$, big restorations: $82.7 \%)(p>0.05)$. Surface roughness and marginal discoloration were the main qualitative deteriorations observed until the final recall. Secondary caries and endodontic complications did not occur in any of the teeth.

Conclusion: Early findings of this clinical study with the two micro-hybrid composite laminate veneers showed similar survival rate and their clinical performance was not significantly influenced when bonded onto intact teeth or onto teeth with existing restorations with the protocol applied.

Keywords: Aesthetics, Adhesion, Clinical trial, Direct composite veneers, Existing composite restorations, Laminate veneer, Silica coating, Surface conditioning 


\section{Introduction}

Laminate veneers, made directly with resin composites or indirectly with ceramics, are indicated to restore hypoplastic enamel and/or dentin, fractured, malformed, malpositioned or discolored teeth since more than 20 years. Direct applications with resin composites are usually quick, inexpensive, and easy to repair compared to ceramic veneers and they can provide acceptable aesthetic results. Yet, both options are less invasive compared to full-coverage crowns.

Survival rate of ceramic laminate veneers are predicted to be $90 \%$ after 10 years of clinical service. ${ }^{1}$ With direct resin composite laminate veneers, clinical studies showed limited longevity due to their susceptibility to staining, wear and fractures. ${ }^{2-4}$ On the other hand, the Cochrane Collaboration concluded that there was no evidence as to whether indirect laminate veneers perform better than direct ones. ${ }^{5}$

During the last two decades, the use of resin composites for aesthetic restorative procedures has increased owing to improvements in adhesive systems and resin composite materials. With the total etch (three-step or etch-and-rinse) and two-step self-etch adhesives, acceptable adhesion to enamel and dentin could be achieved. ${ }^{6-8}$ Bonding to enamel due to micro-mechanical interlocking of resin tags is still considered to be the gold standard where up to $40 \mathrm{MPa}$ is achieved in in-vitro studies, sometimes even exceeding the cohesive strength of the enamel itself. ${ }^{6,9}$ The presence of enamel in restoration margins seals the margins and helps to protect the possible degradation of resin bond to dentin. ${ }^{10}$ In-vitro studies do not always show consistent adhesion results to dentin when etch-and-rinse systems are used. ${ }^{10-12}$ The mixture of inorganic-organic structure of dentin and the technique sensitivity of etch-and-rinse systems are considered to be possible reasons for these variations. After the introduction of more user friendly self-etch

adhesive systems, similar bond strength results to etch-and-rinse systems were reported for dentin. ${ }^{10,13}$ Regarding to adhesion to enamel, additional phosphoric acid etching is still advised in combination with self- 
etch systems. ${ }^{14}$ Among many self-etch adhesives, Clearfil SE Bond (Kuraray Dental, Tokyo, Japan) has been proven to yield reliable results both in-vitro and in-vivo. ${ }^{10,11}$

Direct or indirect laminate veneers are adhered to enamel, enamel/dentin, dentin or discoloured or aged existing resin composites in combination with surrounding enamel and/or dentin. Especially when such existing restorations are present on teeth without any symptoms of caries, clinical dilemma as to whether or not to remove them. While removal often yields to inevitable sound dental tissue removal, leaving the restoration is feared to impair the adhesion. In fact, recent in-vitro studies demonstrated superior compositeto-composite bonding after conditioning the underlying composites with silica coating followed by silanization compared to acid etching and silanization or using air borne particle abrasion with alumina followed by silanization. ${ }^{15-18}$ The process of silanization promotes the wettability of the adherent and reacts with the silica particles, forming covalent bonds. ${ }^{17}$ However, the clinical performance of such conditioning methods on composites is not investigated to date. If a stable bond could be obtained by conditioning the existing restorations, less number of underlying restorations need to be removed which will eventually decrease the restoration cycle.

Owing to advancements in filler technologies, the fillers in resin composites changed from macro or micro particles to hybrid or micro-hybrid particles through which colour stability and strength of these materials are improved. ${ }^{19}$ Although clinical information is available with micro-filled composites up to 3 years, ${ }^{3,4}$ long-term clinical studies are not available with micro-hybrid composites using layering technique. ${ }^{20}$

The objective of this study therefore was to evaluate the clinical performance of direct composite laminate veneers made of two micro-hybrid composites (Enamel Plus HFO and Miris2), bonded to either sound teeth or to teeth with existing composite restorations, in a randomized, split-mouth clinical trial using layering technique. The hypothesis tested were that a) both microhybrid resin composites with their bonding 
agents would function similar in the clinical situation and b) existing composite restorations would not decrease the survival rate of direct laminate veneers.

\section{Materials and methods}

2.1 Study design

The brands, types, manufacturers, chemical compositions and batch numbers of the materials used in this study are listed in Table 1.

In order to avoid possible noticeable differences in case of distinct levels of aging in the materials mainly due to discoloration, in the symmetric teeth, a modified split mouth design was employed where the central incisors received the same type of restoration. Randomization was based on the paired teeth and it was performed using the flip of a coin for the choice of the composite material.

2.2 Inclusion and exclusion criteria

Between June-2007 and March-2011, a total of 23 patients with aged between 29 and 84 years old (6 male, 17 female, mean age: 52.4) received 96 direct composite laminate veneers. Patients recruited for this study were referred from the surrounding local general dental practices. Before entering the trial, all patients were provided with an informed consent form approved by the ethical committee of the university institutional review board (ABR number: NL 14837.042.06). Information was given to each patient regarding the alternative treatment options. The inclusion criteria employed comprised the following: all subjects were required to be at least 18 years old, able to read and sign the informed consent document, physically and psychologically able to tolerate conventional restorative procedures, having no active periodontal or pulpal diseases, having teeth with good restorations, and willing to return for follow-up examinations as outlined by the investigators. Patients with uncontrolled parafunction or presenting insufficient oral hygiene leading to 
caries lesions more than twice a year during the last two years were not included in this study. Non-vitality of the teeth was not an exclusion criteria. ${ }^{4}$

One operator (M.G.) placed all laminate veneers. Existing restorations of good quality, presenting no caries, ditching or marginal staining were not removed prior to tooth preparation. They were rated for their size; restorations, covering more than half of the labial surfaces, were considered as big and the others as small restorations.

\subsection{Tooth preparation}

Before tooth preparations, shade was determined for the two composites using their corresponding biochromatic shade guides under standard light conditions $(6500 \mathrm{~K}, 8$ light intensity, Longlife, Aura, The Netherlands). Magnified loops (x4.2) (Examvision, Rotterdam, The Netherlands) were used for minimal preparations of approximately 0.1 to $0.3 \mathrm{~mm}$ in the cervical and 0.3 to $0.6 \mathrm{~mm}$ in the incisal area, using tapered round-ended diamond burs (no: 637, Dentsply Maillefer, Ballaigues, Switzerland). An incisal overlap of $1 \mathrm{~mm}$ was prepared in cases where translucency was required. All margins were placed supra-gingivally to maintain good periodontal health. At the cervical area, a light chamfer finish line was created and the preparation extended inter-proximally to hide restoration margins. All internal angles were smoothened to reduce stress concentration.

2.4 Direct laminate veneers

Two micro-hybrid layering resin composites (Enamel Plus HFO, Micerium S.p.A., Avegno, Italy and Miris2, Coltene Whaledent, Altstätten, Switzerland) were used randomly. After removal of the minimal required thickness from the labial surface for the composite material, all teeth to be veneered were isolated using a split-rubberdam technique. Contour strips (Contour-Strip, Ivoclar Vivadent, Schaan, Liechtenstein) were placed with the help of wedges interproximally to achieve a smooth restoration outline in the cervical area. Firstly, the existing restorations were silica coated $\left(30 \mu \mathrm{m} \mathrm{SiO}{ }_{2}\right.$, CoJet $^{\circledR}-$ Sand, $3 M$ ESPE AG, Seefeld, 
Germany) using an intraoral air-abrasion device (Dento-Prep ${ }^{T M}$, RøNVIG A/S, Daugaard, Denmark) at a pressure of 2.5 bar from a distance of approximately $10 \mathrm{~mm}$ for 5 seconds. Then, enamel was selectively etched with $38 \% \mathrm{H}_{3} \mathrm{PO}_{4}$ (Ultra-etch, Ultradent, South Jordan, USA) for 30 seconds. After rinsing for 30 seconds and air-drying, a 3-methacryloxypropyltrimethoxy silane coupling agent (MPS) (ESPE ${ }^{\circledR}-S i l$, 3M ESPE AG) was applied on the existing composite restorations and waited for its evaporation for 5 minutes. The adhesive resins (Ena-Bond for Enamel Plus HFO, Clearfil SE Bond for Miris2) were applied with a microbrush according to the manufacturers` instructions. At the cervical area, a dentin shade composite was applied using hand instruments. After photo-polymerization of this layer for 40 seconds, a second increment of enamel shade was applied at the incisal area and photo-polymerized.

When the complete built up was achieved, restorations were contoured using diamond (no: 676, Dentsply Maillefer, Ballaigues, Switzerland) and steel burs (no: 50, Komet, London, UK). Finally, silicon rubbers were used for finishing and polishing (Astropol FP, HP, Ivoclar Vivadent) at 7.500-10.000 rpm under water. The intercuspation was checked in protrusive movements of the mandible. Sequence of conditioning and application protocol is summarized in Table 2. The time spent for each restoration was also noted at the end of every session.

\subsection{Evaluation}

Two calibrated observers who were blinded to the objective of this study performed the evaluations. Both observers evaluated the restorations independently, according to the modified United States Public Health Service (USPHS) criteria (Table 3). After data collection, in case of discrepancies in scoring, restorations were evaluated again, a consensus was reached and this was accepted as the final score. Caries, chipping, debonding, fracture and severe discoloration were considered as absolute failures. Restorations were evaluated at baseline and thereafter every 6 months. Patients were instructed to call upon any kind of failure. Also, digital photographs were made at baseline and follow-up sessions. 


\subsection{Statistical analysis}

Statistical analysis was performed using a statistical software program (SPSS 13.0; SPSS Inc., Chicago, IL, USA). Non-parametric Breslow (Generalized Wilcoxon) and Kaplan-Meier, Log Rank (Mantel-Cox) statistical tests were used to compare the survival curves based on the two resin-composite materials and the size of the existing restorations. Cox regression analysis was used to estimate the hazards of experiencing failure attributable to resin-composite type. $P$ values less than 0.05 were considered to be statistically significant in all tests.

\section{Results}

In total, 7 recalls (every 6 months after baseline) were performed after baseline measurements and no dropout was experienced yielding to the observation of 96 direct resin composite laminate veneers (Enamel Plus HFO: $n=48$; Miris2: $n=48$ ). Patients received laminate veneers for a variety of reasons. Indications involved restoration of discoloured composite restorations being the most common reason $(n=50)$, restoration of worn teeth $(n=13)$, replacement of existing veneers $(n=4)$, and masking discoloured $(n=17)$ or malformed $(n=3)$ and/or misaligned teeth $(n=9)$. The mean observation time was 41.3 months with a minimum observation period of 25 months and maximum 45.7 months. Average treatment time for each direct composite restoration was noted to be approximately 40 minutes which was comparable with the literature. ${ }^{21}$

Thirty-eight of the laminate veneers were on central incisors, 40 on lateral incisors, and 18 on canines in the maxilla. In total, 84 composite laminate veneers were bonded onto existing restorations of which 54 were big and 30 small restorations.

A total of 12 absolute failures were observed in the form of debondings (Enamel Plus HFO: $n=6$ ), fractures (Miris2: $n=2$; Enamel Plus HFO: $n=3$ ) and severe discolorations (Miris2: $n=1$ ). Of the six debondings, while two of them were at the dentin-veneer interface, in the other four, the existing restorations were partially fractured cohesively accompanied with adhesive failures at the dentin-veneer interface. All 4 
fractures presented partially adhesive failures between the tooth and the veneer. Failed veneers were remade employing the adhesive protocol used for Miris2.

Secondary caries and endodontic complications were not observed in any of the restored teeth. Six teeth showed slight post-operative sensitivity (Enamel Plus HFO: $n=2$; Miris2: $n=4$ ) that disappeared after 1 week. Surface roughness (Scores 2 and 3) (Enamel Plus HFO: 1 out of 39, Miris2: 2 out of 45) and marginal discoloration (Scores 2 and 3) (Enamel Plus HFO: 0 out of 39, Miris2: 1 out of 45) were the main qualitative deteriorations observed until the final recall (Table 4). Representative failure types are presented in Figs. 1ad.

Overall, survival rate of the direct composite laminate veneers was $87.5 \%$. The survival rates of the veneers with the two resin composites did not show significant differences [Enamel Plus HFO: 81.2\%, 95\%Cl 34.19; 42.74; 45.76; Miris2: 93.8\%, 95\%Cl 42.53; 45.76] $(P>0.05)$ (Fig. 2a). The presence of existing composite restorations on the prepared teeth did not affect the survival rate significantly (on intact teeth: $100 \%$, on small restorations: $90.6 \%$, on big restorations: $82.7 \%)(P>0.05)$ [Kaplan-Meier, Log Rank (Mantel-Cox) ( $\mathrm{Cl}=95 \%$ 38.95; 43.66)] (Fig. 2b).

Cox regression analysis revealed the overall difference in hazard of using HFO or Miris2 was not significant at $5 \%(p=0.073)$ (Hazard ratio: $3.3 ; 95 \% \mathrm{Cl} 0.895 ; 12.22)$.

\section{Discussion}

The overall survival rate of the two micro-hybrid composites did not show significant differences and existing composite restorations did not decrease the survival rate of direct laminate veneers significantly in this clinical study, yielding to acceptance of both hypotheses. An analysis after a relatively short follow-up period, with mean observation period of 41.3 months, has certain limitations. Although $87.5 \%$ of the restorations did not need any intervention until the end of the observation period, which could be considered clinically 
acceptable, early failures observed in this study should be evaluated carefully. As adhesion plays an important role in the overall performance of composite restorations and especially with veneers where no mechanical retention exists, the durability of the adhesive interface is utmost important for the longevity of such restorations. The adhesive resin Ena-Bond was used for the Enamel Plus HFO as suggested by the manufacturer of this composite together with selective enamel etching. Also, for the two-step self-etch adhesive (Clearfil SE Bond) enamel was selectively etched for the Miris2 system. Six debondings with the Enamel Plus HFO composite could be attributed to the adhesive system used. In a recent in-vitro study, where a microtensile test was used, Ena-Bond delivered superior results with $30 \mathrm{MPa}$ compared to self-etch adhesives on dentin. ${ }^{12}$ In principle, this value should have been appropriate for stable bond. However, adhesive debondings observed in this study, do not correlate with the in-vitro findings. The debondings is usually a consequence of the degradation of the adhesive interfaces. ${ }^{8,10}$ Mainly water sorption is thought to destabilize the adhesive joints. ${ }^{9,17}$ This kind of degradation may have no clinical consequences in a longer duration for restorations where mechanical retention dominates. However, with laminate veneers, adhesion quality of interfaces directly affects the longevity of the whole restoration. Nevertheless, debondings observed in the Enamel Plus HFO composite applied cases indicates the weak link between the adhesive resin and the tooth substrate.

In the case of existing composites, the tooth surface contains at least two types of substrates, namely enamel and/or dentin and the resin composite. The bond strength of the resin composite onto this mixed substrate is complex. The cohesive failure of the existing composite indicates that the strength of the adhesive joint exceeded the cohesive strength of the composite material. All 4 fractures were experienced with laminate veneers bonded onto the existing composites where adhesive failures were observed between the tooth and the veneering composote. Part of the veneer composites however remained on the existing restorations but no cohesive failure in the existing composite was observed. Aged composite substrate 
pretreatment with silica coating and silanization delivered 46-49 $\mathrm{MPa}$ in an in-vitro study by Özcan et al. where microtensile test was used. ${ }^{18}$ These values surpass the dentin bonding and even the enamel bonding obtained with different adhesive promoters. ${ }^{7,13}$ In this study, tendencial more failures were observed with veneers bonded to existing restorations, yet being not significant from other groups. Therefore, a general statement cannot be made on the durability of composite-composite adhesion. Hydrolytic stability of the achieved bond between composites will be further clinically observed.

Surface roughness or marginal discolorations, when not objected by the patient, were not refinished and repolished during the study. Surface roughness change was observed in 1 case out of 39 with Enamel Plus HFO, and in 2 cases out of 45 with Miris2. In some cases, increased surface roughness was also accompanied with discoloration of the composite surface. Roughness and discoloration may be caused by small air entrapments in the outer layer of the composite. In an in-vitro study where the specular gloss and surface roughness was measured before and after artificial aging, Enamel Plus HFO showed minor and Miris2 moderate surface roughness. ${ }^{23}$ In the same study, Enamel Plus HFO perceived a higher gloss than the natural tooth and Miris2 was ranked below the natural tooth after aging procedures. The differences between the materials were attributed to differences in the type of fillers; Enamel Plus HFO contains inorganic fillers and Miris2 glass fillers. The increased filler content changes the handling properties and the material becomes stiffer. Hence, voids and gaps could occur during layering. Shrinkage of the materials itself can also affect the matrix-filler interfaces. ${ }^{24}$ Incomplete or non-uniform silane bonding or the degradation of the silane around the filler particles due to local shrinkage and hydrolysis may result in separation of the fillers from the resin matrix causing porosities along the filler interfaces. ${ }^{22}$ Consequently, surface porosity could increase by time. In a recent study, SEM images of Enamel Plus HFO presented very homogeneous distribution of fine milled submicron glass fillers, with good integration into the surrounding resin matrix but in contrast to Enamel Plus HFO, more small voids were detected in the resin matrix with 
Miris2. ${ }^{23}$ Limited number of USPHS Scores 2 and 3 for surface roughness and marginal disclolorations cannot verify the findings of in-vitro studies. Slightly more frequent Score 1 was observed with Miris2 for marginal discoloration and surface roughness as opposed to Enamel Plus HFO. These scores are considered clinically acceptable restorations that require no intervention according to USPHS criteria. Based on these current results, observations of a previous in-vitro study could be confirmed. ${ }^{23}$

In a clinical study by Welbury in 1991, 289 micro-filled resin composite laminate veneers were placed and followed up to 3 years. ${ }^{3}$ Failures were experienced most frequently due to hard food consumption or bruxism. The most experienced failure types were partial or complete loss of veneers, adhesive failures, marginal staining and poor aesthetics. No signs of abrasive wear were seen. The major deficiencies of the composites used in 1980ies have been overcome by hybrid composites with higher volume filler fraction that allows for reduction of monomers and shrinkage. ${ }^{19,25}$ The combination of silica and glass particles $(<1-10$ $\mu \mathrm{m}$ ) increases the wear resistance and the modulus of elasticity of composite with which increased flexural strength could be obtained. In comparison to the micro-filled composites, hybrid or micro-hybrid composites are more difficult to polish. Nevertheless, the number of incidences with unacceptable surface roughness was limited in this study.

In a 2.5 -year clinical study, Meijering et al. reported an overall survival rate of $78 \%$ for micro-fine direct composites and $94 \%$ for porcelain veneers. ${ }^{4}$ These failures involved both relative and absolute failures. In that study, only $6 \%$ of the direct resin composite restorations had absolute failures. In previous clinical studies, it was not reported whether the restorations were bonded to existing restorations or not. ${ }^{3,4}$ Nonetheless, qualitative observations seem to be similar regardless of the variations in the compositions of resin composites used. Other clinical studies on anterior composite restorations reported 60 to $80 \%$ acceptable Class III and V restorations after 5 years of clinical service. ${ }^{26-29}$ The main reasons for replacement of these restorations were again mainly surface discoloration followed by secondary caries 
and/or fracture of the restoration. Similarly, the major reason for the indication of direct laminate veneers was restoration of discoloured composites that could still be considered as a common problem of resin composites regardless of the improvements in their chemistry.

Besides the physico-chemical properties of resin-based materials and the performance of adhesive promoters, application mode, handling, modeling of such materials especially in the aesthetic zone requires

a long learning curve and training. Dental practitioners should be aware of the applications and limitations of the various resin-based restorative materials. The clinician who applied these restorations has a clinical experience of 5 years. Future clinical studies should consider the material properties as well as the experience of the clinician on the survival of such restorations.

\section{Conclusion}

From this clinical study, the following could be concluded:

1. Clinical performance of the direct composite laminate veneers with the tested two micro-hybrid composites (Enamel Plus HFO versus Miris2) together with their bonding agents did not show significant differences with an overall survival rate of $87.5 \%$ up to maximum 45.7 months.

2. The presence of existing composite restorations on the prepared teeth did not affect the survival rates of the composite laminate veneers significantly during the observation period.

3. Besides absolute failures, surface roughness and marginal discoloration were the common relative failures observed. 


\section{REFERENCES}

1. Peumans M, De Munck J, Fieuws S, Lambrechts P, Vanherle G, Van Meerbeek B. A prospective ten-year clinical trial of porcelain veneers. Journal of Adhesive Dentistry 2004;6:65-76.

2. Walls AW, Murray JJ, McCabe JF. Composite laminate veneers: a clinical study. Journal Oral Rehabilitation 1988;15:439-54.

3. Welbury RR. A clinical study of a microfilled composite resin for labial veneers. International Journal of Paediatric Dentistry 1991;1:9-15.

4. Meijering AC, Creugers NHJ, Roeters FJM, Mulder J. Survival of three types of veneer restorations in a clinical trial: a 2.5-year interim evaluation. Journal of Dentistry 1998;26:563-68.

5. Wakiaga J, Brunton P, Silikas N, Glenny AM. Direct versus indirect veneer restorations for intrinsic dental stains. Cochrane Database Systematic Review 2004;1:CD004347.

6. Munck J de, Landuyt K van, Peumans M, Poitevin A, Lambrechts P, Braem M, Van Meerbeek B. A critical review of the durability of adhesion to tooth tissue: methods and results. Journal of Dental Research 2005;84:118-32.

7. Breschi, Mazzoni A, Ruggeri A, Cadanaro M, Di Lenarda R, De Stafano Dorigo E. Dental adhesion: Aging and stability of the bonded interface. Dental Materials 2008;24:90-101.

8. Vaidyanathan TK, Vaidyanathan J. Recent advances in the theory and mechanism of adhesive resin bonding to dentin: a critical review. Journal of Biomedical Materials Research Part B Applied Biomaterials 2009;88:558-78.

9. Van Meerbeek B, Peumans M, Poitevin A, Mine A, Van Ende A, Neves A, De Munck J. Relationship between bond-strength tests and clinical outcomes. Dental Materials 2010;26:100-21. 
10. De Munck J, Van Landuyt K, Peumans M, Poitevin A, Lambrechts P, Braem M, Van Meerbeek B. A critical review of the durability of adhesion to tooth tissue: Methods and results. Journal of Dental Research 2005;84:118-32.

11. Peumans M, Kanumilli $P$, De Munck J, Van Landuyt K, Lambrechts $P$, Van Meerbeek B. Clinical effectiveness of contemporary adhesives: A systematic review of current clinical trials. Dental Materials 2005;21:864-81.

12. D'Arcangelo C, De Angelis F, D'Amario M, Zazzeroni S, Ciampoli C, Caputi. The influence of luting systems on the microtensile bond strength of dentin to indirect resin-based composite and ceramic restorations. Operative Dentistry 2009;34:328-36.

13. van Meerbeek B, De Munck J, Yoshida Y, Inoue S, Vargas M, Vijay P, Van Landuyt K, Lambrechts P, Vanherle G. Buonocore memorial lecture. Adhesion to enamel and dentin: current status and future challenges. Operative Dentistry 2003;28:215-35.

14. Pashley DH, Tay FR. Aggressiveness of contemporary self-etching adhesives Part II: Etching effect on unground enamel. Dental Materials 2001;17:430-44.

15. Özcan M. The use of chairside silica coating for different dental applications: a clinical report. Journal of Prosthetic Dentistry 2002;87:469-72.

16. Özcan M, Alander P, Vallittu PK, Huysmans MC, Kalk W. Effect of three surface conditioning methods to improve bond strength of particulate filler resin composites. Journal of Materials Science: Materials in Medicine 2005;16:21-7.

17. Matinlinna JP, Lassila LVJ, Vallitu PK. Evaluation of five dental silanes on bonding a luting cement onto silica-coated titanium. Journal of Dentistry 2006;34:721-6. 
18. Özcan M, Barbosa SH, Melo RM, Galhano GAP, Bottino MA. Effect of surface conditioning methods on the microtensile bond strength of resin composite to composite after aging conditions. Dental Materials 2007;23:1276-82.

19. Ferracane JL. Resin composite- State of the art. Dental Materials 2011;27:29-38.

20. Dietschi D, Ardu S, Krejci I. A new shading concept based on natural tooth color applied to direct composite restorations. Quintessence International 2006;37:91-102.

21. Meijering AC, Creugers NHJ, Mulder J, Roeters FJM. Treatment times for three different types of veneer restorations. Journal of Dentistry 1995;23:21-6.

22. Özcan M. Anterior restorations: Direct composites, veneers or crowns? In: Roulet JF, Kappert HF, editors. Statements: Diagnostics and Therapy in Dental Medicine Today and in the Future. New Malden: Quintessence; 2009. p.45-67.

23. Barucci-Pfister N, Göhring TN. Subjective and objective perceptions of specular gloss and surface roughness of esthetic resin composites before and after artificial aging. American Journal of Dentistry 2009;22:102-10.

24. Peumans M, Van Meerbeek B, Lambrechts P, Vanherle G. The 5-year clinical performance of direct composite additions to correct tooth form and position. I. Esthetic qualities. Clinical Oral Investigations 1997;1:12-8.

25. Lutz F, Philips RW. A classification and evaluation of composite resin systems. Journal of Prosthetic Dentistry 1983;50:480-8.

26. Millar BJ, Robinson PB, Inglis AT. Clinical evaluation of an anterior hybrid composite resin over 8 years. British Dental Journal 1997;182:26-30.

27. Van Meerbeek B, Perdigao J, Lambrechts P, Vanherle G. The clinical performance of adhesives. Journal of Dentistry 1998;26:1-20. 
28. Reusens B, D'hoore W, Vreven J. In vivo comparison of a microfilled and a minifilled composite resin in class III restorations: 2-year follow-up. Clinical Oral Investigations 1999;3:62-9.

29. Spinas E. Longevity of composite restorations of traumatically injured teeth. American Journal of Dentistry 2004;17:407-11. 


\section{Captions to the legends and tables:}

Tables:

Table 1. The brand, type, manufacturer, chemical composition and batch numbers of the main materials used in this study.

Table 2. The sequence of conditioning and application protocol for the direct resin composite laminate veneers.

Table 3. List of modified United States Public Health Service (USPHS) criteria used for the clinical evaluations of the restorations.

Table 4. Summaries of USPHS evaluations at baseline and final follow-up for the two composites tested.

\section{Figures}

Figs. 1a-d Representative photos of some failures a) Total adhesive failure between the composite laminate veneer (Enamel Plus HFO) and the tooth 23, b) Fracture of the composite laminate veneer (Enamel Plus HFO) accompanied with adhesive failure on tooth 22, c) Rough surface of the composite on teeth 21 (Miris2) and 22 (Enamel Plus HFO), d) Marginal and surface discoloration on teeth 11 (Miris2) and 12 (Enamel Plus HFO).

Figs. 2a-b. Event-free survival rate of direct resin composite laminate veneers based on a) material (Enamel Plus HFO: $81.2 \%$; $n=48$, events $n=9$ and Miris2: $93.8 \%$; $n=48$, events $n=3$ ) and b) size of the existing restorations they were bonded onto; intact teeth (None), big and small restorations (None: 100\%; $n=12$, events $n=0$; Big: $82.7 \%$; $n=54$, events $n=9$; Small: $90.6 \%$; $n=30$, events $n=3$ ). 


\section{Tables:}

\begin{tabular}{|c|c|c|c|c|}
\hline Brand & Туре & Manufacturer & Chemical composition & $\begin{array}{l}\text { Batch } \\
\text { number }\end{array}$ \\
\hline Enamel Plus HFO & $\begin{array}{l}\text { Micro-hybrid } \\
\text { composite }\end{array}$ & Micerium S.p.A, Avegno, Italy & $\begin{array}{l}\text { bis-GMA, TEGDMA, UDMA } \\
\text { resin } 5.2 \% \text { butandioldimethacrylate, } 66.3 \mathrm{v} \% \\
\text { strontium, aluminium, glass (silanized) } \\
7.6 \mathrm{w} \% \text { siliciumoxide, } 0.3 \mathrm{w} \% \text { pigments }\end{array}$ & 2006103145 \\
\hline Miris2 & $\begin{array}{l}\text { Micro-hybrid } \\
\text { composite }\end{array}$ & $\begin{array}{l}\text { Coltène Whaledent } \mathrm{GmbH} \text {, } \\
\text { Altstätten, Switzerland }\end{array}$ & $\begin{array}{l}\text { bis-GMA, TEGDMA, UDMA } \\
\text { inorganic filler: } 80 \mathrm{wt} \% \text { (65 vol\%), range of } \\
\text { particle size: } 0.02-2.5 \mu \mathrm{m} \text {, barium glass } \\
\text { (silanized), amorphous silica (hydrophobed) }\end{array}$ & 0189343 \\
\hline Ena-Bond & $\begin{array}{l}\text { Resin } \\
\text { adhesive }\end{array}$ & $\begin{array}{l}\text { Micerium S.p.A., Avegno, } \\
\text { Italy }\end{array}$ & $\begin{array}{l}\text { Solution of modified acrylic acid, polyacrylic } \\
\text { acid, methacrylate, catalysts, stabilizers in } \\
\text { ethanol }\end{array}$ & 2008006328 \\
\hline $\begin{array}{l}\text { Clearfil SE Bond } \\
\text { Primer }\end{array}$ & $\begin{array}{l}\text { Self-etching } \\
\text { primer }\end{array}$ & $\begin{array}{l}\text { Kuraray Medical Inc, Tokyo, } \\
\text { Japan }\end{array}$ & $\begin{array}{l}\text { 2-hydroxyethyl methacrylate, water, dyes, } \\
\text { methacryloyloxydecyl dihydrogen phosphate, } \\
\text { hydrophillic aliphatic dimethacrylate, } \\
\text { dl-Camphorquinone, accelerators }\end{array}$ & $00960 \mathrm{~A}$ \\
\hline
\end{tabular}

\begin{tabular}{|c|c|c|c|c|}
\hline $\begin{array}{l}\text { Clearfil SE Bond } \\
\text { Bond }\end{array}$ & $\begin{array}{l}\text { Self-etching } \\
\text { adhesive }\end{array}$ & $\begin{array}{l}\text { Kuraray Medical Inc, Tokyo, } \\
\text { Japan }\end{array}$ & $\begin{array}{l}\text { bis-GMA, accelerators, 2-hydroxyethyl } \\
\text { methacrylate, colloidal silica, } \\
\text { 10-Methacryloyloxydecyl dihydrogen } \\
\text { phosphate, } \\
\text { hydrophillic aliphatic dimethacrylate, } \\
\text { dl-Camphorquinone, initiators }\end{array}$ & $01424 \mathrm{~A}$ \\
\hline Ultra-Etch & $\begin{array}{l}\text { Phosphoric } \\
\text { acid }\end{array}$ & $\begin{array}{l}\text { Ultradent Products Inc, South } \\
\text { Jordan, USA }\end{array}$ & $38 \%$ phosphoric acid & 413277 \\
\hline CoJet $^{(B}$-Sand & Sand & $\begin{array}{l}\text { 3M ESPE AG, Seefeld, } \\
\text { Germany }\end{array}$ & $\begin{array}{l}\text { Aluminium trioxide particles coated with silica, } \\
\text { particle size: } 30 \mu \mathrm{m}\end{array}$ & 165092 \\
\hline ESPE $^{(B)}-S i l$ & $\begin{array}{l}\text { Silane } \\
\text { coupling } \\
\text { agent }\end{array}$ & $\begin{array}{l}\text { 3M ESPE AG, Seefeld, } \\
\text { Germany }\end{array}$ & $\begin{array}{l}\text { 3-methacryloxypropyltrimethoxysilane, } \\
\text { ethanol, ethyl alcohol }\end{array}$ & 189599 \\
\hline
\end{tabular}

Table 1. The brand, type, manufacturer, chemical composition and batch numbers of the main materials used in this study. 


\begin{tabular}{|c|c|}
\hline & \begin{tabular}{c} 
Sequence of Conditioning and Application Protocol \\
\hline $\mathbf{1}$
\end{tabular} \\
\hline $\mathbf{2}$ & Silica coating the existing composite restorations (5 s) \\
\hline $\mathbf{3}$ & Selective acid etching of enamel (30 s) $\left(38 \% \mathrm{H}_{3} \mathrm{PO}_{4}\right)$ \\
\hline $\mathbf{4}$ & Rinsing $30 \mathrm{~s}$ \\
\hline $\mathbf{5}$ & Self-etching primer + Bonding (for Miris2) / Bonding (for Enamel Plus HFO) \\
\hline $\mathbf{6}$ & Photo-polymerization $40 \mathrm{~s}$ \\
\hline $\mathbf{7}$ & Incremental application of dentin shades (Photo-polymerization $40 \mathrm{~s})$ \\
\hline $\mathbf{8}$ & Incremental application of enamel shades (Photo-polymerization $40 \mathrm{~s})$ \\
\hline $\mathbf{9}$ & Occlusion and articulation control \\
\hline $\mathbf{1 0}$ & Finishing and polishing the restorations \\
\hline
\end{tabular}

Table 2. The sequence of conditioning and application protocol for the direct resin composite laminate veneers. 


\begin{tabular}{|c|c|c|}
\hline Category & Score & Criteria \\
\hline \multirow[t]{5}{*}{ Adaptation } & 0 & Smooth margin \\
\hline & 1 & $\begin{array}{l}\text { All margins closed or possess minor voids or } \\
\text { defects (enamel exposed) }\end{array}$ \\
\hline & 2 & $\begin{array}{l}\text { Obvious crevice at margin, dentin or base } \\
\text { exposed }\end{array}$ \\
\hline & 3 & Debonded from one end \\
\hline & 4 & Debonded from both ends \\
\hline \multirow[t]{5}{*}{ Color match } & 0 & Very good color match \\
\hline & 1 & Good color match \\
\hline & 2 & Slight mismatch in color or shade \\
\hline & 3 & Obvious mismatch, outside the normal range \\
\hline & 4 & Gross mismatch \\
\hline Marginal & 0 & No discoloration evident \\
\hline \multirow[t]{3}{*}{ discolouration } & 1 & Slight staining, can be polished away \\
\hline & 2 & Obvious staining, cannot be polished away \\
\hline & 3 & Gross staining \\
\hline \multirow[t]{4}{*}{ Surface roughness } & 0 & Smooth surface \\
\hline & 1 & Slightly rough or pitted \\
\hline & 2 & Rough, cannot be refinished \\
\hline & 3 & Surface deeply pitted, irregular grooves \\
\hline \multirow[t]{6}{*}{ Fracture of restoration } & 0 & No fracture \\
\hline & 1 & Minor crack lines over restoration \\
\hline & 2 & Minor chippings of restoration (1/4 of restoration) \\
\hline & 3 & Moderate chippings of restoration ( $1 / 2$ of restoration) \\
\hline & 4 & Severe chippings ( $3 / 4$ restoration) \\
\hline & 5 & Debonding of restoration \\
\hline \multirow[t]{6}{*}{ Fracture of tooth } & 0 & No fracture of tooth \\
\hline & 1 & Minor crack lines in tooth \\
\hline & 2 & Minor chippings of tooth (1/4 of crown) \\
\hline & 3 & Moderate chippings of tooth ( $1 / 2$ of crown) \\
\hline & 4 & Crown fracture near cementum-enamel line \\
\hline & 5 & Crown-root fracture (extraction) \\
\hline \multirow[t]{2}{*}{ Wear of restoration } & 0 & No wear \\
\hline & 1 & Wear \\
\hline \multirow[t]{2}{*}{ Wear of antagonist } & 0 & No wear \\
\hline & 1 & Wear of antagonist \\
\hline \multirow[t]{2}{*}{ Caries } & 0 & $\begin{array}{l}\text { No evidence of caries continuous along the } \\
\text { margin of the restoration }\end{array}$ \\
\hline & 1 & $\begin{array}{l}\text { Caries evident continuous with the margin of } \\
\text { the restoration }\end{array}$ \\
\hline \multirow[t]{4}{*}{ Post-operative sensitivity } & 0 & No symptoms \\
\hline & 1 & Slight sensitivity \\
\hline & 2 & Moderate sensitivity \\
\hline & 3 & Severe pain \\
\hline
\end{tabular}

Table 3. List of modified United States Public Health Service (USPHS) criteria used for the clinical evaluations of the restorations. 


\begin{tabular}{|c|c|c|c|c|c|}
\hline \multirow{2}{*}{\multicolumn{2}{|c|}{$\overline{C \text { Criteria }}$}} & \multicolumn{2}{|l|}{ Baseline } & \multicolumn{2}{|l|}{ Final Recall } \\
\hline & & $\begin{array}{l}\text { Enamel Plus HFO } \\
(n=48)\end{array}$ & $\begin{array}{l}\text { Miris2 } \\
(\mathrm{n}=48)\end{array}$ & $\begin{array}{l}\text { Enamel Plus HFO } \\
(n=39)\end{array}$ & $\begin{array}{l}\text { Miris2 } \\
(n=45)\end{array}$ \\
\hline $\begin{array}{l}\text { Adaptation of } \\
\text { Restoration }\end{array}$ & $\begin{array}{l}0 \\
1 \\
2 \\
3 \\
4\end{array}$ & $\begin{array}{l}47 \\
1 \\
- \\
- \\
-\end{array}$ & $\begin{array}{l}46 \\
2 \\
- \\
- \\
-\end{array}$ & $\begin{array}{l}35 \\
3 \\
1 \\
- \\
- \\
\end{array}$ & $\begin{array}{l}36 \\
8 \\
1 \\
- \\
-\end{array}$ \\
\hline Color Match & $\begin{array}{l}0 \\
1 \\
2 \\
3 \\
4\end{array}$ & $\begin{array}{l}34 \\
11 \\
3 \\
- \\
-\end{array}$ & $\begin{array}{l}32 \\
11 \\
5 \\
- \\
-\end{array}$ & $\begin{array}{l}29 \\
7 \\
3 \\
- \\
-\end{array}$ & $\begin{array}{l}32 \\
10 \\
5 \\
- \\
-\end{array}$ \\
\hline $\begin{array}{l}\text { Marginal } \\
\text { Discoloration }\end{array}$ & $\begin{array}{l}0 \\
1 \\
2 \\
3\end{array}$ & $\begin{array}{l}48 \\
- \\
- \\
-\end{array}$ & $\begin{array}{l}48 \\
- \\
- \\
-\end{array}$ & $\begin{array}{l}29 \\
10 \\
- \\
-\end{array}$ & $\begin{array}{l}33 \\
11 \\
1 \\
-\end{array}$ \\
\hline $\begin{array}{l}\text { Surface } \\
\text { Roughness }\end{array}$ & $\begin{array}{l}3 \\
0 \\
1 \\
2 \\
3\end{array}$ & $\begin{array}{l}44 \\
4 \\
- \\
-\end{array}$ & $\begin{array}{l}47 \\
1 \\
- \\
-\end{array}$ & $\begin{array}{l}26 \\
12 \\
1 \\
-\end{array}$ & $\begin{array}{l}25 \\
18 \\
2 \\
-\end{array}$ \\
\hline $\begin{array}{l}\text { Fracture of } \\
\text { Restoration }\end{array}$ & $\begin{array}{l}0 \\
1 \\
2 \\
3 \\
4 \\
5\end{array}$ & $\begin{array}{l}48 \\
- \\
- \\
- \\
- \\
-\end{array}$ & $\begin{array}{l}48 \\
-- \\
- \\
- \\
-\end{array}$ & $\begin{array}{l}36 \\
1 \\
2 \\
- \\
- \\
-\end{array}$ & $\begin{array}{l}43 \\
1 \\
1 \\
- \\
- \\
-\end{array}$ \\
\hline Fracture of Tooth & $\begin{array}{l}0 \\
1 \\
2 \\
3 \\
4 \\
5\end{array}$ & $\begin{array}{l}48 \\
- \\
- \\
- \\
- \\
-\end{array}$ & $\begin{array}{l}48 \\
- \\
- \\
- \\
- \\
-\end{array}$ & $\begin{array}{l}39 \\
- \\
- \\
- \\
- \\
-\end{array}$ & $\begin{array}{l}45 \\
- \\
- \\
- \\
- \\
-\end{array}$ \\
\hline $\begin{array}{l}\text { Wear of } \\
\text { Restoration }\end{array}$ & $\begin{array}{l}0 \\
1\end{array}$ & $\begin{array}{l}48 \\
-\end{array}$ & $\begin{array}{l}48 \\
-\end{array}$ & $\begin{array}{l}38 \\
1\end{array}$ & $\begin{array}{l}45 \\
-\end{array}$ \\
\hline Wear of Antagonist & $\begin{array}{l}0 \\
1\end{array}$ & 48 & $\begin{array}{l}48 \\
-\end{array}$ & 39 & $\begin{array}{l}45 \\
-\end{array}$ \\
\hline Caries & $\begin{array}{l}0 \\
1\end{array}$ & $\begin{array}{l}48 \\
-\end{array}$ & $\begin{array}{l}48 \\
-\end{array}$ & $\begin{array}{l}39 \\
-\end{array}$ & $\begin{array}{l}45 \\
-\end{array}$ \\
\hline $\begin{array}{l}\text { Post-operative } \\
\text { Sensitivity }\end{array}$ & $\begin{array}{l}0 \\
1 \\
2 \\
3\end{array}$ & $\begin{array}{l}44 \\
2 \\
- \\
- \\
\end{array}$ & $\begin{array}{l}46 \\
4 \\
- \\
- \\
\end{array}$ & $\begin{array}{l}39 \\
- \\
- \\
-\end{array}$ & $\begin{array}{l}45 \\
- \\
- \\
-\end{array}$ \\
\hline
\end{tabular}

Table 4 Summaries of USPHS evaluations at baseline and final follow-up for the two composites te 

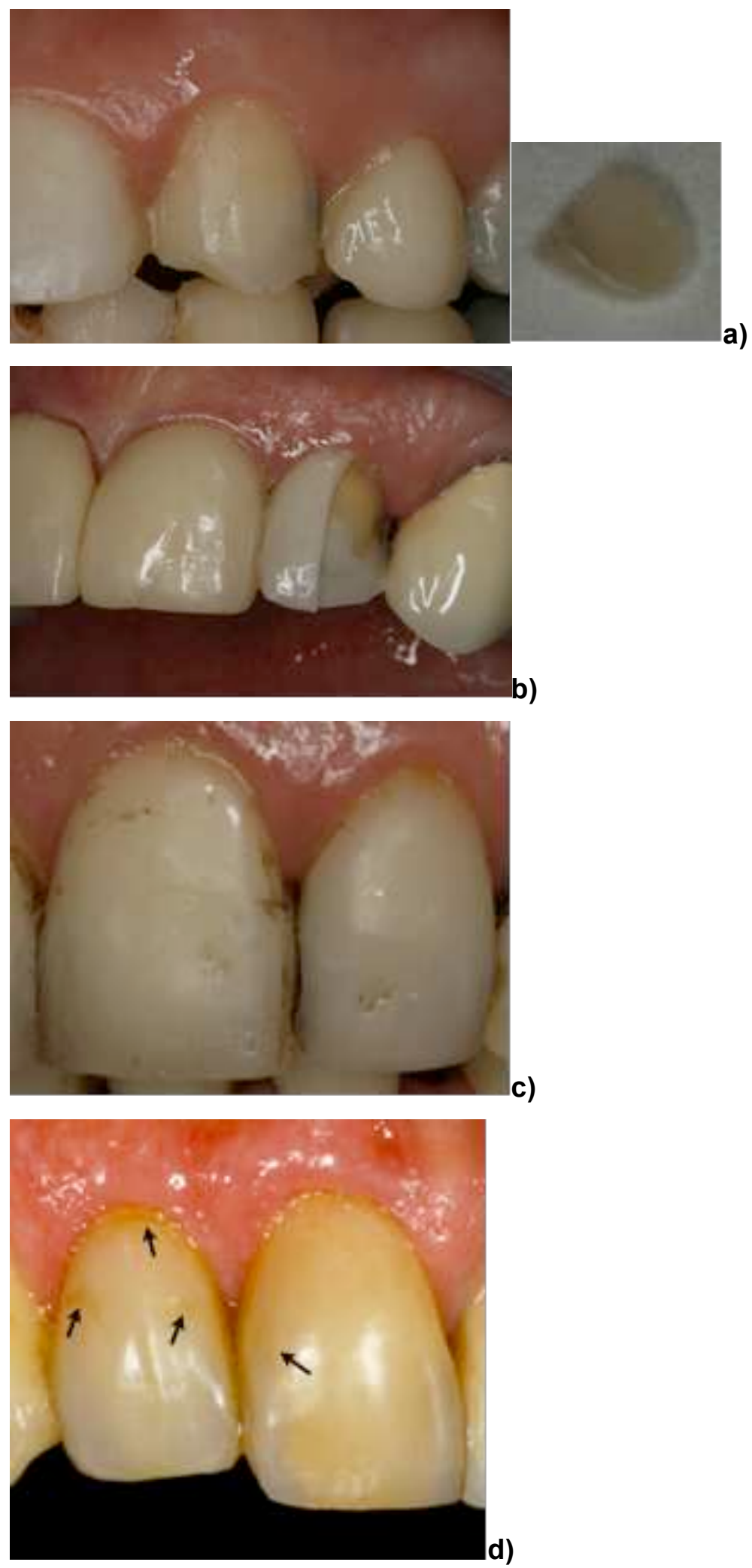

Figs.1a-d Representative photos of some failures a) Total adhesive failure between the composite laminate veneer (Enamel Plus HFO) and the tooth 23, b) Fracture of the composite laminate veneer (Enamel Plus HFO) accompanied with adhesive failure on tooth 22, c) Rough surface of the the composite on teeth 21 
(Miris2) and 22 (Enamel Plus HFO), d) Marginal and surface discoloration on teeth 11 (Miris2) and 12 (Enamel Plus HFO).
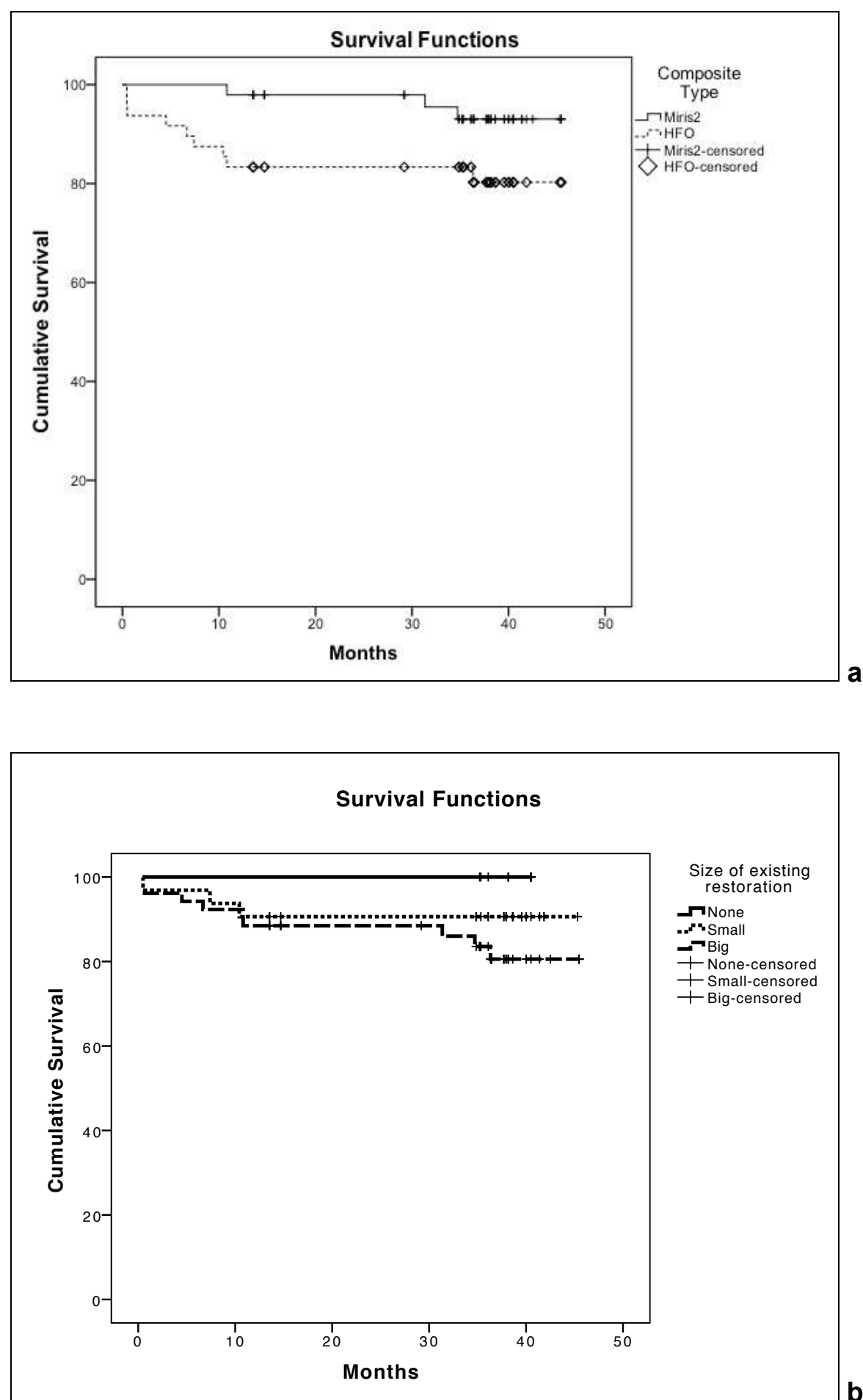

b)

Figs. 2a-b. Event-free survival rate of direct resin composite laminate veneers based on a) material (Enamel Plus HFO: $81.2 \% ; n=48$, events $n=9$ and Miris2: $93.8 \% ; n=48$, events $n=3$ ) and b) size of the existing restorations they were bonded onto; intact teeth (None), big and small restorations (None: 100\%; $n=12$, events $n=0$; Big: $82.7 \%$; $n=54$, events $n=9$; Small: $90.6 \%$; $n=30$, events $n=3$ ). 